\title{
Factors Associated with Parent-Adolescent Communication on Sexual and Reproductive Health Issues Among Secondary and Preparatory School Students in Mekelle City, North Ethiopia
}

\author{
Zemenu Yohannes ${ }^{1}$, Yonas Girma ${ }^{2}$, Shimels Hussien ${ }^{3}$, Bazezew Fekad ${ }^{4}$ \\ ${ }^{1}$ Department of Midwifery, School of Nursing and Midwifery, College of Medicine and Health Sciences, Hawassa University, Hawassa, \\ Ethiopia \\ ${ }^{2}$ Center of International Reproductive Health Training (CIRHT), Bahir Dar University, Bahir Dar, Ethiopia \\ ${ }^{3}$ World Health Organization (WHO), MCH/Nutrition Cluster, National Consultant, Addis Ababa, Ethiopia \\ ${ }^{4}$ Department of Gynecology and Obstetrics, College of Medicine and Health Sciences, Bahir Dar University, Bahir Dar, Ethiopia
}

\section{Email address:}

zemenu2013@gmail.com (Zemenu Y.),yonastile@gmail.com (Yonas G.), shimelsh@gmail.com (Shimels H.), bazezewfekad@yahoo.au (Bazezew F.)

\section{To cite this article:}

Zemenu Yohannes, Yonas Girma, Shimels Hussien, Bazezew Fekad. Factors Associated with Parent-Adolescent Communication on Sexual and Reproductive Health Issues Among Secondary and Preparatory School Students in Mekelle City, North Ethiopia. Science Discovery. Vol. 3, No. 6, 2015, pp. 55-61. doi: 10.11648/j.sd.20150306.13

\begin{abstract}
Background: Adolescence is a period of transition from childhood to adulthood where new behaviors are more easily learned than when in adulthood. sexual and reproductive health are among the most essential aspects of life for adolescents, but due to cultural taboo and political sensitivities, they often obtain little attention in public health policy discussion. In Ethiopia, sexual and reproductive health problems of adolescents are increasing from time to time and this is related with most parents do not feel happy to discuss about sexual issues with their adolescents and early sexual commencement. Therefore, the aim of this study was to identify factors affecting parent adolescent communication on sexual and reproductive health issues among Secondary and Preparatory school students in Mekelle city, North Ethiopia. Method: School based Cross sectional study was conducted among high school students in Mekelle city from August 1 to 30, 2014. High school students in Mekelle of age 10-19 years enrolled in grade 9th-12th for the academic year 2013-2014 was selected from the source population using multistage sampling. Simple random sampling technique was used to select 537 Students from 9th-12th grades. Data were entered using Epi Info version 3.5.1 was exported and analyzed by SPSS version 20. Bivariate and multivariate logistic regressions were used to identify independent predictors of adolescent- parent communications. Results: More than half (57.6\%) respondents had discussed on sexual and reproductive health issues with their parents. In the multivariate analysis adolescents who had illiterate mother were found to be 0.43 and 0.46 times less likely to have communication on sexual and reproductive health issues than such adolescent with mothers who have attained secondary and higher degree and/or qualification, respectively ( $\mathrm{AOR}=0.43 ; 95 \% \mathrm{CI}: 0.22-0.84$ ) and (AOR $=0.46 ; 95 \% \mathrm{CI}$ : 0.24 0.89).Those adolescents communicate HIV/AIDS with relatives (aunts, uncles, grand-mothers and grand-fathers) 4 times more likely to discuss sexual and reproductive health issues than such adolescents who communicate with peers ( $\mathrm{AOR}=3.94$, 95\% CI: 1.98, 7.82), These Adolescents discussed sexual intercourse 3 times more likely to communicate sexual and reproductive health than such adolescent who don't communicate (AOR=2.88, 95\%CI: 1.89-4.38). Conclusion and recommendations: In this study parent-adolescent communications on sexual and reproductive health issues were low.so that it is vital to develop a comprehensive national adolescent sexual and reproductive health and development strategy to implement in school, family and community level to increase parent-adolescent communication.
\end{abstract}

Keywords: Adolescent, Communication, Sexual, Reproductive Health, Parent, Ethiopia 


\section{Introduction}

Globally around 1.8 billion young people between ages of 10-24 years and represent $27 \%$ of the world population. Adolescence is a period of transition from childhood to adulthood where new behaviors are more easily learned than when in adulthood. Sexuality and reproductive health are among the most essential aspects of life for adolescents, but due to cultural taboo and political sensitivities, they often obtain little attention in public health policy discussion $[1,2]$. Worldwide each year an estimated 14 million adolescents give birth and more than $90 \%$ of these live births occur in developing countries. Adolescents in the Sub Saharan Africa region have disproportionately affected by HIV, unwanted pregnancy, unsafe abortion, low family planning utilization rates and limited knowledge of reproductive health $(\mathrm{RH})$ services $[3,4]$.

Parent-child communication about sexual and reproductive health is an important proximal reproductive health consequence .where as in Africa sex-related discussion between parent and adolescent are taboo including in Ethiopia believed that telling adolescents about sex and instruction them how to keep themselves would make them sexually active and culturally shameful $[5,6]$.

Studies showed that poor sexual and reproductive health can have other health effects, on the other hand economic and social consequences, which combine have a profound influence on individuals, families, populations and countries. Indeed, currently global and national government crunches troubling involve directly or indirectly problems associated to unintended pregnancy, teenage pregnancy, unplanned births, HIV and other sexually transmitted infections (STIs), and maternal mortality and morbidity. Hence, while essential improvement has been made in several areas of sexual and reproductive health, predominantly as differences in health indicators and consequences are broadening, both within and between countries [7].

In Ethiopia, Adolescents and young people ages 10 to 24 are the biggest group ever to be entering adulthood it accounts 21 million represents $30 \%$ of total population. According to national adolescent and youth reproductive health strategy of Ethiopia, specifically directed to addressing their most persistent needs of reproductive health including early sexual debut, age at first marriage, early child bearing, unwanted pregnancy, abortion, knowledge and use of family planning methods, HIV/AIDS and STIs. Unfortunately, it is restricted at health facility level and rural areas who have limited access to targeted reproductive health services. . Sexual and reproductive health service has not been provided at school, at community and at family level [8, 9, 10]. In Ethiopia, Sexual and reproductive health problems of adolescents are increasing from time to time and this is related with most parents do not feel happy to discuss about sexual issues with their adolescents and early sexual commencement $[9,11]$. There is little data available about parent-adolescent communication and associated factors in the study area.

Therefore, the aim of this study was to identify factors affecting parent adolescent communication on sexual and reproductive health issues among Secondary and Preparatory school students in Mekelle city, North Ethiopia 2014.

\section{Methods and Materials}

\subsection{Study Area and Period}

The study was conducted in Mekelle City from August 1 to 30, 2014. Mekelle is located in the northern part of the country and 783 Kilometers from Addis Ababa (Capital city of Ethiopia). It covers 28 square kilometers and had an estimated population of 300,000 [12].Educational coverage of Mekelle city population was 74\%. In 2014 there were a total of 24 secondary and preparatory schools, out of this eight government high schools and sixteen private high schools .There were 21,173 students in the academic year 2013-2014. From this $45.1 \%$ were males and $54.89 \%$ were females [13].

\subsection{Study Design}

Institution based cross sectional study was conducted to obtain primary data on factors associated with ParentAdolescent Communication on Sexual and Reproductive Health issues among Secondary and Preparatory School Students in Mekelle city, North Ethiopia.

\subsection{Sample Size Determination}

Sample size was determined using single population proportion formula by considering assumptions of had ever discussed of parent-adolescent communicating on sexual and reproductive health issues with estimated $69.5 \%$ [14], desired precision of $5 \%$, and $95 \%$ confidence level. Design effects of one point five plus $10 \%$ for non-response rate, a total of 537 students were recruited for the study.

\subsection{Sampling Procedure}

Series of sampling procedures were used to select study subject. First, multi stage sampling procedure was employed to select representative sample of students in the selected high schools. From 24 schools that have grade 9 th-12th, six high schools (three governments and three private) were randomly selected by lottery method. The sample size was proportional allocated to each stratum (Grade 9, 10, 11 and12). Among 21,173 students, 537 study participants were selected by simple random sampling (lottery method) using the roster as sampling frame. Students who cannot speak and write Tigrigna, blind and or seriously sick at the time of data collection were excluded from the study.

\subsection{Data Collection}

Pre-tested an anonymous self-administered structured questionnaire was prepared after reviewing relevant literature 
[15-22]. The questionnaire was first prepared in English and then translated to Tigrigna, the local language of the respondents in the study area. The data were collected using self-administered structured questionnaire. The questionnaires were administered to all students during the data collection period, and who met the inclusion criteria.

\subsection{Data Quality Control}

Data were collected by six data collectors who completed grade 12 other than the study schools, speak and write Tigrigna. Data collectors were trained for two day on the objectives of the study, sampling procedure, questionnaire, checking the completeness of questionnaire. Questionnaire was pre-tested at Wukiro high school to assess clarity, flow and consistency, and revised prior to the start of data collection. Data completeness and consistency was checked by the investigators.

\subsection{Data Analysis}

To ensure the quality of the data, all the filled questionnaire were checked for incompleteness and inconsistency. Data were entered using Epi Info version 3.5.1 and exported to SPSS version 20 for statistical analysis. Descriptive statistical analysis was used to compute frequency, percentage and mean for independent and dependent variables. Binary logistic regression analysis was used to ascertain the association between explanatory variables and outcome. Variables with significant association in the bivariate analysis were entered in to multivariate analysis to determine independent associated factor of adolescent-parent communication on sexual and reproductive health issues. Variables with $\mathrm{P}$ value less than 0.05 was considered as statistically significant. Finally the results were presented in texts, tables and graphs.

\subsection{Ethical Consideration}

Ethical approval and clearance was taken from institutional review board of College of Medicine and Health Sciences, Mekelle University. The Regional Education Bureau gave permission to conduct the study in each selected schools in the study area. After explaining the purpose of the study, verbal informed consent was obtained from respondents before data collection. The right to withdraw from the study at any time was also assured. Coding was used to eliminate names and other personal identification of respondents throughout the study process to ensure participants confidentiality.

\section{Results}

A total of 521 students with a response rate of $97 \%$ had participated in this study.

\subsection{Socio-Demographic and Economic Character Tics}

Table 1 shows the socio demographic characteristics of the respondents. Hence, the study participated school adolescents more than half $(55.7 \%)$ were females and the mean age of students was 16.6 years, $(\mathrm{SD}=1.3$, range 13 - 19 years $)$. Almost half (48.8\%) students reported their family sizes were greater than five.

Table 1. Socio-economic and demographic characteristics among secondary and preparatory school students in Mekelle city, North Ethiopia. August 2014.

\begin{tabular}{|c|c|c|}
\hline Variable & Number $n=521$ & Percent \\
\hline \multicolumn{3}{|l|}{$\operatorname{Sex}(n=521)$} \\
\hline Male & 231 & $44.3 \%$ \\
\hline Female & 290 & $55.7 \%$ \\
\hline \multicolumn{3}{|l|}{ Age $(n=521)$} \\
\hline $13-16$ & 267 & $51 \%$ \\
\hline $17-19$ & 254 & $49 \%$ \\
\hline \multicolumn{3}{|l|}{ Grade $(n=521)$} \\
\hline Grade 9 & 144 & $27.6 \%$ \\
\hline Grade10 & 157 & $30.1 \%$ \\
\hline Grade 11 & 117 & $22.5 \%$ \\
\hline Grade 12 & 103 & $19.8 \%$ \\
\hline \multicolumn{3}{|l|}{ Religion $(\mathrm{n}=521$ ) } \\
\hline Orthodox Christian & 464 & $89.1 \%$ \\
\hline Muslim & 47 & $9.1 \%$ \\
\hline Protestant & 10 & $1.9 \%$ \\
\hline \multicolumn{3}{|l|}{ Ethnicity $(\mathrm{n}=521)$} \\
\hline Tigray & 502 & $96.4 \%$ \\
\hline Amhara & 16 & $3.1 \%$ \\
\hline Afar & 1 & $.2 \%$ \\
\hline \multicolumn{3}{|l|}{$\begin{array}{l}\text { Living arrangements of adolescent } \\
(\mathrm{n}=521)\end{array}$} \\
\hline With both parents & 388 & $74.5 \%$ \\
\hline With mother only & 88 & $16.9 \%$ \\
\hline With father only & 13 & $2.5 \%$ \\
\hline Relative & 10 & $1.9 \%$ \\
\hline \multicolumn{3}{|l|}{ Mother's educational status $(\mathrm{n}=521)$} \\
\hline Illiterate & 83 & $15.9 \%$ \\
\hline Read and write & 122 & $23.4 \%$ \\
\hline Primary school & 46 & $8.8 \%$ \\
\hline Secondary school & 87 & $16.7 \%$ \\
\hline Tertiary school & 158 & $30.3 \%$ \\
\hline Not live & 25 & $4.8 \%$ \\
\hline \multicolumn{3}{|l|}{ Father's educational status $(n=521)$} \\
\hline Illiterate & 37 & $7.1 \%$ \\
\hline Read and write & 105 & $20.2 \%$ \\
\hline Primary school & 42 & $8.1 \%$ \\
\hline Secondary school & 78 & $15 \%$ \\
\hline Tertiary school & 206 & $28.4 \%$ \\
\hline Not live & 53 & $10.2 \%$ \\
\hline \multicolumn{3}{|l|}{ Family size $(\mathrm{n}=521)$} \\
\hline$<5$ & 262 & $50.2 \%$ \\
\hline 5 and above & 259 & $48.8 \%$ \\
\hline \multicolumn{3}{|l|}{ Estimated family income $(\mathrm{n}=521)$} \\
\hline$<1000$ & 10 & $2.1 \%$ \\
\hline $1000 \_2000$ & 14 & $2.68 \%$ \\
\hline$>2000$ & 68 & $129 \%$ \\
\hline Don't know & 443 & $85 \%$ \\
\hline
\end{tabular}

*Others indicate those who belong to the ethnic group like Oromo, Gurage...etc

**Others indicate those who live alone, with friends, or other than either of their parents or relatives. 


\subsection{Communications on Sexual and Reproductive Health Issues}

More than half $300(57.6 \%)$ respondents were reported that it was important to discuss on sexual and reproductive health issues with their parents out of this 199 (38.2\%) were communicate with mothers and 101(19.4\%) with fathers. Majority $66.7 \%$ of adolescent discussed with mothers on HIV/AIDS issues. On the other hand more than half (59\%) Adolescents were discussed with friend on physiology and psychological change during puberty.

Table 2. Adolescents communication with their parents and friends, sisters, brothers and others in different topics of sexual and reproductive health issues, Mekelle city,North Ethiopia, August 2014.

\begin{tabular}{|c|c|c|c|c|c|c|c|c|}
\hline \multirow{2}{*}{ Topic of discussion } & \multicolumn{4}{|c|}{ With Father and mother } & \multicolumn{4}{|c|}{ With whom they had discussed } \\
\hline & No $(\%)$ & Yes $(\%)$ & Father (\%) & Mother (\%) & *Friend (\%) & *Sister (\%) & *Brother (\%) & $* *$ Relatives $(\%)$ \\
\hline Contraceptive & $337(64.7)$ & $184(35.3)$ & $57(10.9)$ & $127(24.4)$ & $184(35.3)$ & $154(29.6)$ & $105(20.2)$ & $35(6.7)$ \\
\hline Sexual intercourse & $335(64.3)$ & $186(35.7)$ & $60(11.5)$ & $126(26.2)$ & $248(47.6)$ & $100(19.2)$ & $76(14.6)$ & $97(18.6)$ \\
\hline Unwanted pregnancy & $292(56)$ & $229(44)$ & $59(11.3)$ & $170(32.6)$ & $254(48.8)$ & $113(21.7)$ & $67(12.9)$ & $87(16.7)$ \\
\hline Premarital sex & $288(55.3)$ & $233(44.7)$ & $67(12.9)$ & $166(31.9)$ & $252(48.4)$ & $101(19.4)$ & $84(16.1)$ & $84(16.1)$ \\
\hline $\begin{array}{l}\text { physiological and } \\
\text { psychological changes seen in } \\
\text { puberty }\end{array}$ & $250(48)$ & $271(52)$ & $82(15.7)$ & $189(36.3)$ & $308(59.1)$ & $130(25)$ & $90(17.3)$ & $60(11.5)$ \\
\hline
\end{tabular}

*Multiple responses were possible

${ }^{* *}$ Relatives- indicated that with Grand-mother, grand-father, uncle, aunt

\subsection{Adolescents' Reasons for not Discussing with Their Parent on SRH}

A total of 221(42.4\%) Adolescents were reported that they didn't discuss with parents in at least one topics of SRH. Majority of respondents $(366,70.2 \%)$ did not discuss to parents on condom issues. The reason was either parents didn't know and shameful were $114(21.9 \%)$ and $107(20.5 \%)$ respectively.

Table 3. Adolescents' major reasons for not discussing with their parent in Mekelle city, North Ethiopia, August 2014.

\begin{tabular}{|c|c|c|c|c|c|c|c|c|}
\hline \multirow[t]{2}{*}{ Topic of discussion } & \multicolumn{8}{|c|}{ The Reason for Not Discussing } \\
\hline & $\begin{array}{l}\text { Culturally } \\
\text { unacceptable } \\
(\%)\end{array}$ & $\begin{array}{l}\text { Shameful } \\
(\%)\end{array}$ & $\begin{array}{l}\text { Parents less } \\
\text { communication } \\
\text { skill }(\%)\end{array}$ & $\begin{array}{l}\text { Parents lack of } \\
\text { knowledge }(\%)\end{array}$ & $\begin{array}{l}\text { Embarrassing } \\
(\%)\end{array}$ & $\begin{array}{l}\text { Are not good } \\
\text { listeners (\%) }\end{array}$ & $\begin{array}{l}\text { Do not } \\
\text { know }(\%)\end{array}$ & $\begin{array}{l}\text { *Others } \\
(\%)\end{array}$ \\
\hline Contraceptive & $45(8.6)$ & 93(17.9) & $18(3.5)$ & $56(10.7)$ & $16(3.1)$ & $25(4.8)$ & $82(15.2)$ & $2(.38)$ \\
\hline HIV/AIDS & $17(3.3)$ & $46(8.8)$ & $13(2.5)$ & $26(5)$ & $10(1.9)$ & $15(2.9)$ & $56(10.7)$ & $14(2.67)$ \\
\hline Sexual intercourse & $33(6.3)$ & $108(20.7)$ & $18(3.5)$ & $36(6.9)$ & $17(3.3)$ & $21(4)$ & $76(14.6)$ & $26(4.99)$ \\
\hline Unwanted pregnancy & $22(4.2)$ & $73(14)$ & $20(3.8)$ & $32(6.1)$ & 19(3.6) & $22(4.2)$ & $84(16.1)$ & $20(3.84)$ \\
\hline Premarital sex & $22(4.2)$ & $80(15.4)$ & $15(2.9)$ & $25(4.8)$ & $23(4.4)$ & $24(4.6)$ & $79(15.2)$ & $20(3.84)$ \\
\hline Condom & $38(7.3)$ & $107(20.5)$ & $22(4.2)$ & $39(7.5)$ & $5(1)$ & $20(2.8)$ & $114(21.9)$ & $21(4.03)$ \\
\hline $\begin{array}{l}\text { Physiological and } \\
\text { psychological changes } \\
\text { seen in puberty }\end{array}$ & $12(2.3)$ & $74(14.2)$ & $15(2.9)$ & $30(5.8)$ & $19(3.6)$ & $22(4.2)$ & $60(11.5)$ & $18(3.45)$ \\
\hline
\end{tabular}

Others $=$ not time, not living together, parent dead.

\subsection{Factors Affecting Parent-Adolescent Communication on Sexual and Reproductive Health}

Factors affected parents' adolescent communication on sexual and reproductive health issues. The bivariate logistic regression showed that communication on sexual and reproductive health had significant associated with mother's educational status; communicate other than parents on HIV/AIDS issues with peers, sisters, brothers and relatives (aunts, uncle's grand-mothers, and grand-fathers), communicate contraceptive issues with sisters, discussed sexual intercourse issues and late adolescent age groups.

In the multivariate analysis Adolescents, who had illiterate mother were found to be 0.43 and 0.46 times were less likely to have communication on sexual and reproductive health issues than such adolescents with mothers who have attained secondary and higher degree and/or qualification, respectively $(\mathrm{AOR}=0.43 ; 95 \% \mathrm{CI}: 0.22-0.84)$ and $(\mathrm{AOR}=0.46 ; 95 \% \mathrm{CI}$ : 0.24-0.89). These adolescents communicate HIV/AIDS with relatives (aunts, uncles, grand-mothers and grand-fathers) 4 times more likely to discuss sexual and reproductive health issues than those who communicate with peers $(\mathrm{AOR}=3.94$, 95\%CI: 1.98, 7.82), Such adolescents discussed sexual intercourse 3 times more likely to communicate sexual and reproductive health than these adolescents who don't communicate $(\mathrm{AOR}=2.88,95 \% \mathrm{CI}$ : 1.89-4.38). 
Table 4. Predictors Parent-Adolescent Communication on Sexual and Reproductive Health in Mekelle City, North Ethiopia, August 2014.

\begin{tabular}{|c|c|c|c|c|c|}
\hline \multirow{2}{*}{ Variables } & \multicolumn{2}{|c|}{ Communication on SRH } & \multicolumn{2}{|l|}{ OR $(95 \% \mathrm{CI})$} & \multirow[t]{2}{*}{ P-Value } \\
\hline & Yes & No & Crude & Adjusted & \\
\hline \multicolumn{6}{|l|}{ Mothers educational status } \\
\hline Illiterate & $38(45.8 \%)$ & $45(54.2 \%)$ & 1 & 1 & \\
\hline Read and write only & $65(53.3 \%)$ & $57(46.7 \%)$ & $.74(.42-1.29)$ & $.79(.44-1.43)$ & \\
\hline Primary school & $27(58.7 \%)$ & $19(41.3 \%)$ & $.59(.28-1.23)$ & $.50(.23-1.11)$ & \\
\hline Secondary school & $55(63.2 \%)$ & $32(36.8 \%)$ & $.49(.26-.91)^{*}$ & $.43(.22-.84)^{*}$ & .013 \\
\hline Diploma & $31(52.5 \%)$ & $28(47.5 \%)$ & $.76(.39-1.49)$ & $.88(.43-1.79)$ & \\
\hline Degree and/or Qualification & $67(67.7 \%)$ & $32(32.3 \%)$ & $.40(.22-.74)^{*}$ & $.46(.24-.89)^{*}$ & .020 \\
\hline No mothers & $17(68.0 \%)$ & $8(32.0 \%)$ & $.39(.15-1.02)$ & $.33(.12-.91)$ & \\
\hline \multicolumn{6}{|c|}{ Those Adolescents communicate HIV/AIDS other than parents } \\
\hline Peers & $157(59.2 \%)$ & $108(40.8 \%)$ & 1 & 1 & \\
\hline Sisters & $72(65.5 \%)$ & $38(34.5 \%)$ & $.767(.48-1.22)$ & $1.01(.58-1.74)$ & \\
\hline Brothers & $53(62.4 \%)$ & $32(37.6 \%)$ & $.878(.53-1.45)$ & $1.05(.61-1.81)$ & \\
\hline Relatives* & $15(27.3 \%)$ & $40(72.7 \%)$ & $3.87(2.04-7.36)^{*}$ & $3.93(1.98-7.82)^{*}$ & .000 \\
\hline \multicolumn{6}{|c|}{ Those Adolescents communicate contraceptive issues with sisters } \\
\hline Yes & $99(64.3 \%)$ & $55(35.7 \%)$ & $1.48(1.01-2.19)^{*}$ & $1.56(.97-2.49)$ & \\
\hline No & $201(54.8 \%)$ & $166(45.2 \%)$ & 1 & 1 & \\
\hline \multicolumn{6}{|c|}{ Those Adolescents discussed Sexual intercourse } \\
\hline Yes & $139(74.7 \%)$ & $47(25.3 \%)$ & $3.196(2.16-4.74)^{*}$ & $2.88(1.89-4.38)^{*}$ & .000 \\
\hline No & $161(48.1 \%)$ & $174(51.9 \%)$ & 1 & 1 & \\
\hline \multicolumn{6}{|l|}{ Late Adolescent } \\
\hline $13-16$ & $142(53.2 \%)$ & $125(46.8 \%)$ & $.69(.49-.98)^{*}$ & $.78(.53-1.14)$ & \\
\hline $17-19$ & $158(62.2 \%)$ & $96(37.8 \%)$ & 1 & 1 & \\
\hline
\end{tabular}

Relatives $^{*}=$ aunts, uncles, grandmothers and grandfathers

${ }^{*}$ Statistically significant $(\mathrm{p}$-value $<0.05)$ Unmarked= not significant

\section{Discussion}

This study examined factors associated with parentadolescent communication regarding reproductive health issues in Mekelle secondary \& preparatory school students, Tigray Northern Ethiopia. The prevalence of parentadolescent communication on sexual and reproductive health issues among adolescents in this study was $57.6 \%$. This finding is slightly low as compared to study is conducted in Nekmete $65.5 \%$, [15]. But higher than compared to the study is done in Benishangul gumuz region (Bullen woreda) 28.9\%, Debre Marcos (36.9\%), Dire Dawa (37\%) and Harer (28.76\%) [16-19]. this might be due to the difference in socio-demographic, accessing sexual reproductive health information.

In our study mothers communicate on sexual and reproductive study with adolescents 199 (38.2\%) were higher than fathers 101 (19.4\%). A study done in Nigeria mothers and fathers spoke to their children about sexual issues equally [20]. This might be difference in culture and back ground of parents.

In this study $70.2 \%$ of Adolescents did not discuss about condom, $21.9 \%$ of reason was unknown. Which is slightly lower than the study was done in Tehran $78 \%$ did not discuss by embarrassment [21].This might be due to the difference in cultural or religious influence.

In this study unwanted pregnancy $56 \%$ did not discuss, $16.1 \%$ due to unknown reason. Similar study is done in
Bullen woreda $35.2 \%$ did not discuss on unwanted pregnancy due to shame full [16]. The difference might be due to the time of the study difference and easily available to emergency contraceptive and condom in Mekelle than in Bullen.

In our study a total of 221(42.4\%) adolescents were reported that they didn't discuss with parents in at least one topics of sexual and reproductive health issues, the main reason for not communicating was culturally unacceptable, shameful, parents less communication skill, Parents lack of knowledge, Embarrassing, parents are not good listeners and do not know the reason. This results was consistent study finding of dire dawa, harar and other African country [18, 19]

This might be due to the fact that sexual discussions are believed to be a taboo issue in several African societies.

The result of multiple logistic regression models shown that adolescent discussed about SRH with illiterate mothers were found to be 0.43 and 0.46 times less likely to have communication on sexual and reproductive health issues than these adolescent with mothers who have attained secondary and higher degree and/or qualification, respectively $(\mathrm{AOR}=0.43 ; 95 \% \mathrm{CI}: 0.22-0.84)$ and $(\mathrm{AOR}=0.46 ; 95 \% \mathrm{CI}$ : $0.24-0.89$ ). This study was consistent with study done in Harar and East Wollega zone [19, 22]. This might be due to the difference in knowledge, attitude and retrieving evidence about sexual and reproductive health issues.

Those adolescents communicate HIV/AIDS with relatives 
(aunts, uncles, grand-mothers and grand-fathers) 4 times more likely to discuss sexual and reproductive health issues than such adolescents who communicate with peers $(\mathrm{AOR}=3.94,95 \% \mathrm{CI}: 1.98,7.82)$, this finding were discrepancy with study done in E/Wollega zone, West Ethiopia [22]. This might be due to adolescents perceive family members keep private mysteries and close relationship than peers.

There were significant association between parent adolescent's sexual and reproductive issues and sexual intercourse communication. This study result was consistent with study done in Debremarcos, Dire dawa [17.18]. This may be due to the participants who have some understanding might be more enthusiastic to communicate sexual and reproductive issues.

Strength and Limitation: The strength of this study was adaptation of materials to the Ethiopian context. Sampling technique employed the simple random sampling to achieve high response rate. For better validity of the test, appropriate test statistics were used. The limitations of this study were based on self-reported information, which is subjected to reporting errors, and recall biases. This study is done to assess parent adolescent communication were based on adolescents' perceptions, which may not reflect what parents or parent figures were actually doing and Additional qualitative study should be done on adolescents and parents communication.

\section{Conclusion}

In our study shows that low parent -adolescent communications on sexual and reproductive health issues. Adolescents were discussed about sexual and reproductive health issues more with mother than fathers. The main reasons for not communicated was culturally unacceptable, shameful, parents less communication skill, parents lack of knowledge, embarrassing, parents are not good listeners and do not know the reason. Parent's education, adolescents communicate HIV/AIDS with relatives, adolescents discussed sexual intercourse was a significant factor for parent-adolescent communication on SRH issues.

\section{Recommendations}

In order to address adolescent's sexual and reproductive health issues and provide standard information and services, it is vital to develop a comprehensive national adolescent sexual and reproductive health and development strategy. It is important to reassure and empower parents to start to communicate with their adolescent on sexual matters while the adolescents are still in late childhood or early teenage years, before they become sexually active. Further study recommended conducting to examine what triggers, quality and timing of parents-adolescents communication on sexuality and reproductive health related issues and the effect of communication on safe sexual behaviors.

\section{Acknowledgement}

I am very thankful to goes to all school staffs, data collectors', supervisor and the people of the study area for consenting, participation and cooperation in this study.

\section{Funding Statement}

No fund was received from any foundation or institution

\section{References}

[1] WHO, UNFP, PATH: Essential Medicines Reproductive Health: march 2006 http://www.who.int/medicines/publications/EssMeds_RHealth .pdf accessed date January 12, 2014.

[2] Jejeebhoy SJ: Sexual and reproductive health of young people. Expanding the research and program agenda. 2006. Available from http://hivaidsclearinghouse.unesco.org/search/resources/bie p op_rev_jejeebhoy. Pdf accessed on May 10, 2014.

[3] World Health Organization: Adolescent pregnancy: a culturally complex issue. Bull World Health Organ 2009, 87(6):405-484. Geneva Switzerland.

[4] Nolin MJ, Petersen KK. Gender differences in parent-child communication about sexuality: an exploratory study. J Adolesc Research 1992; 7:59-79.

[5] W Evans, K Davis, C Umanzor, K Patel and M Khan. "Evaluation of Sexual Communication Message Strategies." Reproductive Health. vol. 8:15, 2011.

[6] Hallman K: Socio-economic Disadvantage and Unsafe sexual behaviours among young men and women in South Africa. Population Council: The Population Council, Population Research Division No 190; 2004. www.popcouncil.org/publications/wp/prd/rdwplist.html. accessed date feb20,2014.

[7] Sneha Barot: The Need for a Revitalized National Research Agenda On Sexual and Reproductive Health Guttmacher Policy Review: 14: 1, 2011.

[8] Ministry of Health (MOH). 2004a. National Strategy for Child Survival in Ethiopia.

[9] Federal Democratic Republic of Ethiopia Ministry of Health: National Reproductive Health Strategy 2006 - 2015. Addis Ababa, Ethiopia; $2006 . \quad$ www.pheethiopia.org/admin/uploads/attachment-161National_RH_strat[1].pdf. (accessed on 2/8/2014).

[10] Berhane F, Berhane Y, Fantahun M: Adolescents' Health service utilization pattern and preferences: consultation for reproductive health problems and mental stress are less likely. EthioP J Health Dev 2005, 19(1):29-36

[11] Lisa D: Lieberman: early predictors of sexual behavior: implications for young adolescents and their parents. Perspect Sex Reprod Health 2006, 38(2):112-114.

[12] CSA, ORC Macro: Ethiopian Demographic and Health Survey 2011. Addis Ababa: Central Statistical Authority of Ethiopia and Ministry of Health; 2011. 
[13] Mekelle city education bureau record and documentation 2013.

[14] W. D. Tesso, M. Fantahun, and F. Enquselassie, "Parentyoung people communication about sexual and reproductive health in East Wollega Zone, West Ethiopia: implications for interventions," Reproductive Health, vol. 9, article 13, 2012.

[15] Sime A, Wirtu D: Premarital sexual practice among school adolescents in Nekemte town East Wollega, Ethiop J Health Dev 2008, 22(2):167-173.

[16] Gebre Yesus Desalegn, Fantahun Mesganaw Assessing communication on sexual and Reproductive health issues among high school Students with their parent Bullen woreda benishangul gumuz region North West Ethiopia, Ethiop J Health Dev 2010, 24(2):89-95.

[17] Shiferaw et al.: Assessment of adolescents' communication on sexual and reproductive health matters with parents and associated factors among secondary and preparatory schools' students in Debremarkos town, North West Ethiopia. Reproductive Health 2014 11:2.

[18] Ayalew et al.: Adolescent - parent communication on sexual and reproductive health issues among high school students in Dire Dawa, Eastern Ethiopia: a cross sectional study. Reproductive Health 2014 11:77.
[19] Tesfaye et al.: Factors Affecting Parent-Adolescent Discussion on Reproductive Health Issues in Harar, Eastern Ethiopia: A Cross-Sectional Study. Hindawi Publishing Corporation Journal of Environmental and Public Health Volume 2014, Article ID 102579, 7 pages http://dx.doi.org/10.1155/2014/102579 accessed date march8,2014

[20] Katrina Berg , Christina J. Sun \& Stella Babalola (2012) Predictors of parent-child communication among a nationally representative sample in Nigeria, SAHARA-J: Journal of Social Aspects of HIV/AIDS: An Open Access Journal, 9:2, 95-103 http://dx.doi.org/10.1080/17290376.2012.683583 accessed date march18,2014

[21] Mohammad-Reza Mohammadi, MD Siamak Alikhani, MD Farideh K. Abadi Farahani, PhD, Alireza Bahonar, PhD Parents' Attitudes towards Adolescent Boy's Reproductive Health Needs and Practice in Tehran 2013.

[22] W. D. Tesso, M. Fantahun, and F. Enquselassie, "Parentyoung people communication about sexual and reproductive health in East Wollega Zone, West Ethiopia: implications for interventions," Reproductive Health, vol. 9, article 13, 2012. 